\title{
MARGINAL BONE EVALUATION AND SOFT TISSUE RESPONSE TO TITANIUM DENTAL IMPLANTS WITH ZIRCONIA COLLAR VERSUS TITANIUM IMPLANTS WITH TITANIUM COLLAR PLACED IN ESTHETIC ZONE (RANDOMIZED CLINICAL TRIAL)
}

\author{
Amr M. Mousa*, Magdy M. Kamel**, Akram A. Al-awady***
}

\begin{abstract}
Objective: This study aimed at comparing clinically and radiographically the marginal bone loss and soft tissue response to titanium dental implants with Zirconia collar versus titanium implants with titanium collar placed in esthetic zone. Subjects and methods: Twenty non-smoking patients (ranging from 22 to 43 years) participated in this randomized clinical study. Patients were randomly assigned into one of 2 groups (10 patients each): patients who received two-piece, one-stage, titanium implants with zirconia collar (Periosave, Z1 Conic, TBR Implants Group, France) will processed as a treatment group (Group I), patients who received two-piece, one-stage, titanium implants with titanium collar will processed as a control group (Group II). Clinical and radiographic parameters including Modified plaque index, Modified bleeding index, Crestal bone loss were reassessed at 9 months after surgery. Results: Specifically, marginal peri-implant hard tissue changes that occurred using an implant system with zirconium collar (Group I), in comparison with another types with titanium collar (Group II) were minimal and with no significant difference during the first 9 months after implant installation. Conclusion: The use of titanium implant with transmucosal zirconium collar (Z1 TBR implant) did not show statistical significance in comparison to titanium implant with titanium collar in terms of limitation of crestal resorption usually seen after loading.
\end{abstract}

KEY WORDS: Titanium dental implants with zirconia collar, marginal bone, soft tissue response

\section{INTRODUCTION}

The improved understanding in material-cell interactions results in a high degree of predictability in the clinical success of biomaterials used for dental implants ${ }^{(1,2)}$. Titanium has been established as the first-choice material for endosseous implants because of its chemical-physical properties and its biocompatibility ${ }^{(3,4)}$.

Restorations in the anterior esthetic zone present significant challenges in both the surgical and prosthetic phases of implant dentistry and many types of implants require transmucosal abutments to retain implant restorations. In these cases, the grey color of the titanium is transmitted through the peri-implant tissues causing patient discomfort. The use of ceramic abutments in methods with submerged implants allows the minimization of the gray color associated with metal components ${ }^{(5)}$.

Submerged implants, on the other hand, evidenced limits connected to the operative phases: a second surgical step, longer clinical times, and the irreversibility of the prosthetic structure. Therefore, some previous studies compared non-submerged healing implants, also defined as one-stage implants or transmucosal healing implants, with submerged healing implants, also defined as two-stage implants. These studies, found no differences in

\footnotetext{
* B.D.S, 2010, Faculty of Oral and Dental Medicine, Ain Shams University, Cairo, Egypt.

** Associate Professor, Faculty of Dental Medicine, Department of Periodontology, Al Azhar University, Cairo, Egypt. *** Professor, Faculty of Dental Medicine, Department of Periodontology, Al Azhar, University, Cairo, Egypt.
} 
the long- term prognosis of endosseous dental implants, promising important clinical advantages for the one-stage surgery technique ${ }^{(6)}$.

The use of a new implant with a white transmucosal ceramic collar allowed the combination of the advantages offered by transmucosal implant methods with a one-stage technique with natural transparency and increased biocompatibility at the transmucosal portion. Zirconia is an advanced ceramic used in the bone medical field due to its important mechanical properties and tissue biocompatibility. In addition, zirconia has been shown to reduce bacterial adhesion ${ }^{(8)}$ and plaque accumulation ${ }^{(9)}$.

We can define hybrid implant as an excellent substitute of conventional implants in pure titanium, since these former appear on one hand, to ensure the physical properties of titanium and on other, the cosmetics and antibacterial properties of the zirconium. Moreover, the use of this hybrid type of implants ensures, if properly positioned, a connective tissue seal and a structural integrity with the prosthetic device. The performance of a Zirconium collar implant that literature report to show biocompatibility and connective tissue adhesion similar to that seen on the machined titanium surface ${ }^{(10)}$, however with limited plaque formation and of course better esthetics ${ }^{(11)}$.

The esthetic outcome has become the main focus of interest in esthetically sensitive areas, as implant survival and success rates are high ${ }^{(12)}$. Ideally, successful implant-supported restorations should imitate the appearance of natural teeth ${ }^{(13)}$. The condition of the peri- implant soft tissue appears to be the critical determinant ${ }^{(14)}$. The implant-supported restoration should be in symmetry with the reference tooth. The level of the peri-implant soft tissue, which influences the crown length, its color and texture are decisive for the 'natural' appearance of implant-supported single-tooth replacements ${ }^{(15)}$.
The esthetic outcome is proposed by an aesthetic assessment measures; pink esthetic score and white esthetic score (PES/WES) that is based on established tools by Furhauser (2005) ${ }^{(16)}$ and Belser

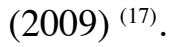

A minimum score of 12 of 20 is required to consider the implant successful from an aesthetics point of view. The new scoring system facilitates a qualitative objective assessment of the implant's aesthetic outcome, and enables clinicians to measure their performance against a set target ${ }^{(16,17)}$.

In this study, we performed preliminary clinical evaluations of transmucosal healing implants with and without a zirconia collar, placed in esthetic zone.

\section{SUBJECTS AND METHODS}

Two types of solid screw transmucosal healing implants with rough endosseous surfaces T.B.R. implants. The endosseous surface was titanium, while the transmucosal collar was titanium or titanium covered by a zirconia ring. The ceramic ring was ayttria stabilized medical grade zirconium dioxide.

The implants used for the clinical studies, in relation to bone height disposal, had an intraosseous length ranging from 10.5 to $15.5 \mathrm{~mm}$, and concerning the bone width disposal, had an intraosseous diameter from 3.5 to $5 \mathrm{~m}$, were inserted in 8 patients (4 males and 4 females) with an average age 32 years (range from 22 to 43 years) were included in this study.

The included subjects were selected from the outpatient clinic of Department of Oral Medicine, Periodontology, Diagnosis and Oral Radiology, Faculty of Dental Medicine (Boys - Cairo),Al-Azhar University. Research procedures were explained to all patients, and they signed the informal consent. 


\section{Inclusion criteria:}

- Age should be at least 18 years old

- The subjects with missing teeth in esthetic area will be included in the study.

- Patient's cooperation, motivation and good oral hygiene.

\section{Exclusion Criteria:}

- Smoking

- Alcohol and drug abuse

- Systemic diseases such as uncontrolled diabetes and hypertension.

- Bruxism and parafunction.

- Pregnancy.

- Psychiatric disorders.

- Presence of active infection.

- Any long-term medication conceivably affecting periodontal tissues as nonsteroidal inflammatory drugs, glucocorticoids, cyclosporine.

- Inability to adhere to planned follow up appointments.

Patient grouping: Patients were randomly divided in two equal groups:

Group 1: patients who received two-piece, one-stage, titanium implants with zirconia collar (Periosave, Z1 Conic, TBR Implants Group, France) will processed as a treatment group.

Group 2: patients who received two-piece, onestage, titanium implants with titanium collar will processed as a control group (Periosave, M Conic, TBR Implants Group, France).

\section{Presurgical Therapy}

All subjects will undergo standardized diagnostic and treatment planning before surgery. All the patients selected for the study will undergo phase
I therapy which included education, motivation, proper oral hygiene instructions, scaling and root planning for all teeth and periodontal treatment to provide an oral environment more favorable to wound healing.

Cone beam CT will be used before surgery to give us the necessary radiographic information about bone quality, 3D analysis of the alveolar ridge at the implant position, proximity to anatomical structures, and implant simulation.

\section{Surgical Procedures}

Two types of titanium screw transmucosal healing implants with rough endosseous surfaces were used. For both types, the endosseous surface was titanium, while the transmucosal collar was titanium or titanium covered by a zirconia ring (Z1 implants, T.B.R. France). The ceramic ring was ayttria stabilized medical grade zirconium dioxide.

The implants used for the clinical studies, in relation to bone height disposal, had an intraosseous length ranging from 10.5 to $15.5 \mathrm{~mm}$, and concerning the bone width disposal, had an intraosseous diameter from 3.5 to $5 \mathrm{~mm}$

Implant insertion was performed according to manufacturer's instructions. On submerged installation procedures were performed. the surgical procedures were carried out under local anesthesia employing a low-trauma surgical technique. All patients received preoperative antibiotic prophylaxis 2 hours prior to surgery.

Paracrestal incisions with releasing incisions were done at surgical sites and Full-thickness flaps were reflected exposing the alveolar ridge, Sequential drills were used until the 3.5 diameter final drill under constant irrigation and flaps were closed by interrupted sutures using 3"0" silk, figures (1-4). 


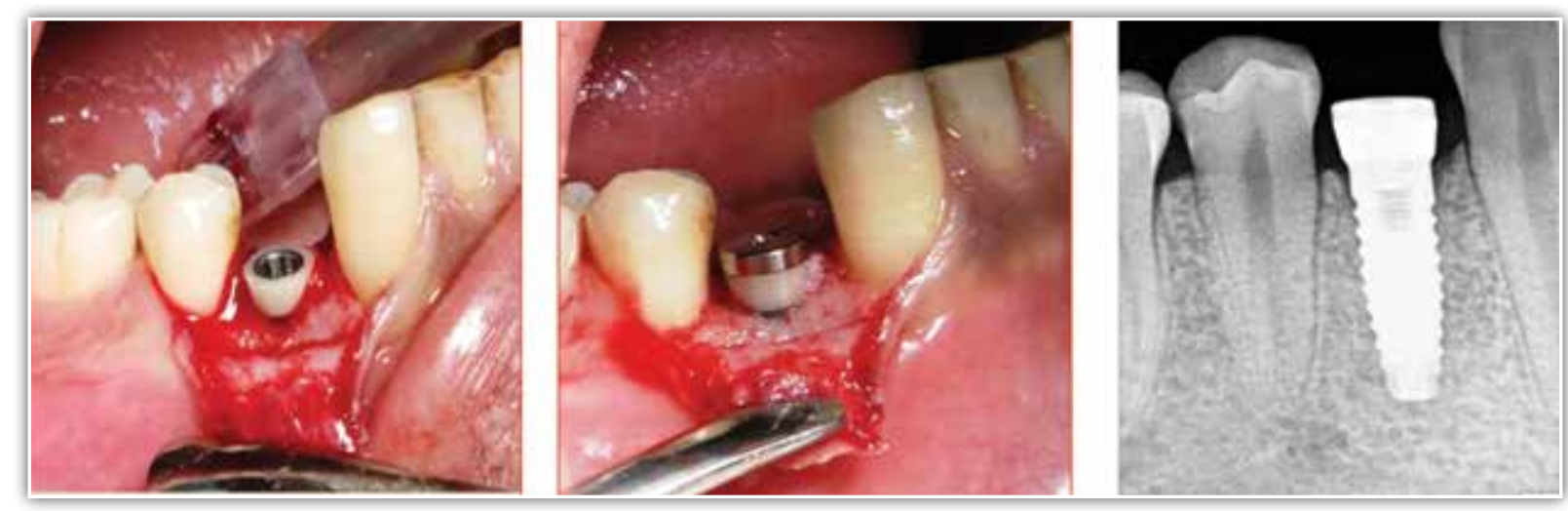

Fig (1): Zirconium collar implant

Fig (2): Digital periapical radiograph (base line)

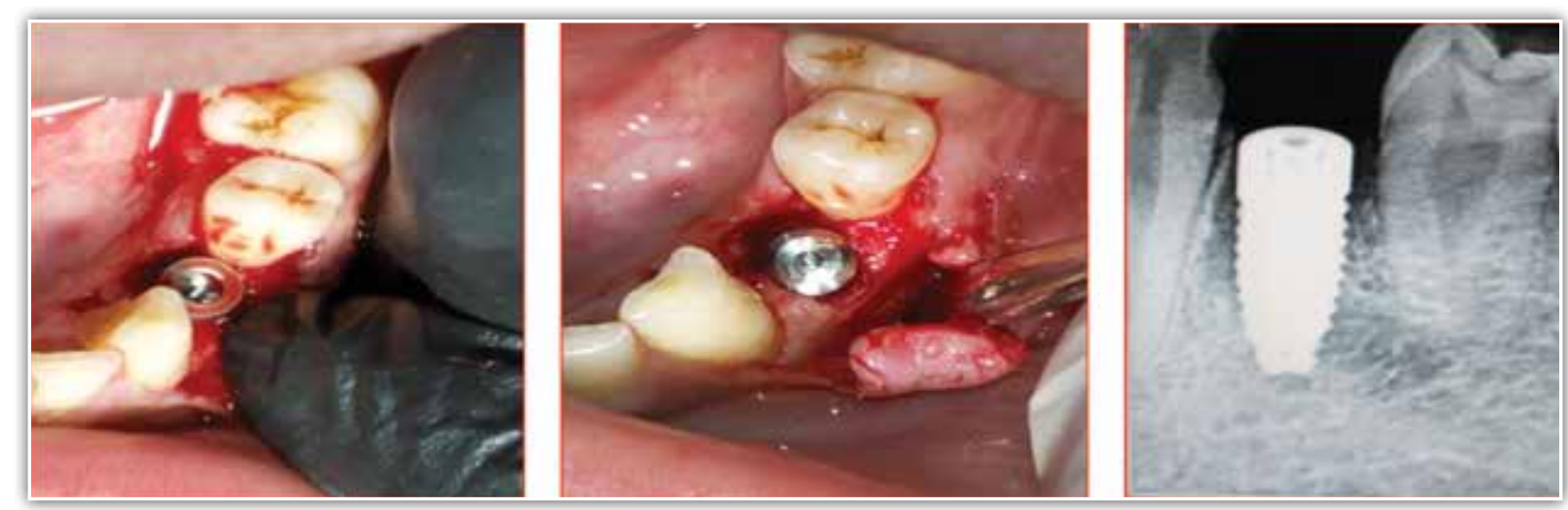

Fig. (3) : Titanium collal implant

Fig (4): Digital periapical radiograph (base line)

\section{RESULTS}

\section{Statistical analysis of the data}

Numerical data were explored for normality by checking the distribution of data and using tests of normality (Kolmogorov-Smirnov and Shapiro- Wilk tests). Crestal bone loss data showed parametric distribution while Modified Plaque Index (MPII) and Modified Bleeding Index (MBI) data showed non-parametric distribution.

Numerical data were presented as mean, median, standard deviation (SD), minimum, maximum and 95\% Confidence Interval (95\% CI) values.
For parametric data; Student's t-test was used to compare between the two groups.

For non-parametric data; Mann-Whitney U test was used to compare between the two groups. Friedman's test was used to study the changes by time in MPLI and MBI scores. Wilcoxon signedrank test with Bonferroni's adjustment was used for pair-wise comparisons when Friedman's test is significant.

The significance level was set at $\mathrm{P} \leq 0.05$. Statistical analysis was performed with IBM $^{\circledR}$ SPSS $^{\circledR}$ Statistics Version 20 for Windows. 
TABLE (1): Descriptive statistics of crestal bone loss (mm) after 9 months recorded from the two groups.

\begin{tabular}{|c|c|c|c|c|c|c|c|}
\hline \multirow[b]{2}{*}{ Group } & \multirow[b]{2}{*}{ Mean } & \multirow[b]{2}{*}{ SD } & \multirow[b]{2}{*}{ Median } & \multirow[b]{2}{*}{ Minimum } & \multirow[b]{2}{*}{ Maximum } & \multicolumn{2}{|c|}{ 95\% CI } \\
\hline & & & & & & Lowerbound & Upper bound \\
\hline Group I & 0.53 & 0.13 & 0.53 & 0.40 & 0.70 & 0.40 & 0.66 \\
\hline Group II & 0.71 & 0.16 & 0.68 & 0.55 & 1.00 & 0.54 & 0.88 \\
\hline
\end{tabular}

\section{Crestal bone loss}

Results of crestal bone loss $(\mathrm{mm})$ of the two studied groups are presented in Table $(1,2)$. It was evident that Group I is showed Mean of $0.53 \pm 13$ while Group II showed Mean of $0.7 \pm 0.16$. The Comparison between the two groups showed no statistically significant difference between amounts of crestal bone loss in the two groups after 9 months (Table 2) and (Fig.5).

TABLE (2): Mean, standard deviation (SD) values and results of Student's t-test for comparison between crestal bone loss $(\mathrm{mm})$ in the two groups

\begin{tabular}{|c|c|c|c|c|}
\hline \multicolumn{2}{|c|}{ Group I } & \multicolumn{2}{c|}{ Group II } & \multirow{2}{*}{ P-value } \\
\cline { 1 - 3 } Mean & SD & Mean & SD & \\
\hline 0.53 & 0.13 & 0.71 & 0.16 & $\mathbf{0 . 0 6 1}$ \\
\hline
\end{tabular}

*: Significant at $P \leq 0.05$

(B) IBM Corporation, NY, USA.

(B) SPSS, Inc., an IBM Company.

\section{DISCUSSION}

Replacing single missing teeth, in particular in the anterior region, always presents a challenge. Patients commonly oppose the preparation of intact teeth as abutments for a fixed partial denture. Other treatment options, including resin-bonded restorations, orthodontics, and removable partial

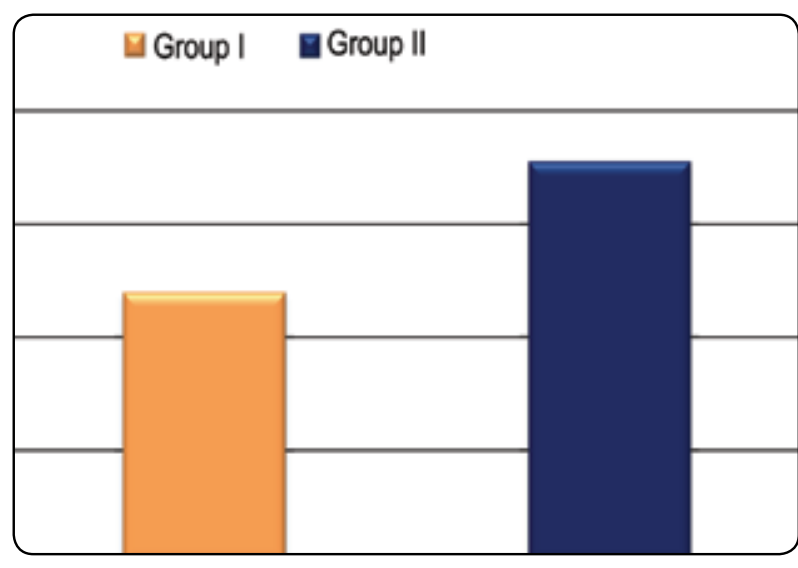

Fig. (5): Bar chart representing mean crestal bone loss in the two groups.

dentures, have been proven to be less than ideal, and there is a considerable interest in replacing missing teeth with implant supported crowns ${ }^{(18-20)}$.

However, using conventional titanium (Ti) implants as abutments for tooth replacements, the grayish color of the Ti implant may often be perceived through the peri-implant mucosa impairing aesthetic outcomes in particular in the presence of a thin mucosal biotype ${ }^{(21-22) .}$ Furthermore, there are reports that metals, including $\mathrm{Ti}$, are able to induce a nonspecific immune modulation and autoimmunity ${ }^{(23)}$.

Highly sensitive immunologic in vitro tests have demonstrated sensitization to Titanium ${ }^{(24)}$. Clinical implications and relevance of these observations are at present not understood. Because of potential immunological and possible aesthetic compromises using Ti implants, novel implant technologies, 
including ceramic implants, are being developed, maintaining the characteristics that gave the $\mathrm{Ti}$ implants their high success rates. ${ }^{(25)}$

However, ceramics are known to be sensitive to shear and tensile loading, and surface flaws may lead to early failure. This disadvantage made it difficult to apply all ceramics for the fabrication of dental implants. One such implant material, aluminum oxide, was used, for example, with the Tübingen Implant (26) but because of its insufficient physical properties, it was withdrawn from the market. Therefore, ceramic implants imply a high risk for fracture, and a study on their strength is needed.

The oral cavity has a natural biofilm, heterogeneous in structure, and often taking the form of an extracellular matrix, made up of micro-organisms existing symbiotically with the periodontal tissue. This balance within the intra-oral environment is characteristic of good oral health.

The functional and aesthetic rehabilitation of dental arches by means of implantology has progressively been replacing more conventional treatments involving removable prosthesis over the years. When implants are fitted, the balance of the intraoral environment is disturbed, potentially leading to peri-implant disease and inflammatory reactions accompanied by bone loss around the implant. Indeed, peri-implant diseases currently represents the main source of medium and longterm implant complications ${ }^{(25)}$.

Studies have shown that $48 \%$ of implants and $77 \%$ of patients had mucositis and that in $16 \%$ of cases, peri-implantitis occurred 9 to 14 years after fitting of the implant. According to Fransson et al. (2005), implants fitted and followed up over a period of at least 5 years entailed progressive bone loss in $28 \%$ of patients.

Peri-implantitis, which is caused by pathogenic bacteria, can be avoided by drastically reducing any bacterial proliferation or colonization in the transmucosal section of the implant site. This analysis led to the development of PERIOSAVE® implants, which ensure durability of the dental implants while protecting the periodontium. ${ }^{(26)}$

Colonization by bacteria can occur at implant sites, primarily: after several procedures on the same implant site, with constant problems in maintaining correct levels of asepsis, when soft tissue and healing are badly managed, depending on the types of materials used.

The Zirconia Y-TZP (Yttria Tetragonal Zirconia Polycristal) technology incorporated into the transgingival zirconia collar of the PERIOSAVE® $\mathrm{Z} 1$ implants resolves all these issues. Its excellent mechanical properties make it the ideal material for present and future implantology. The zirconia collar of the PERIOSAVE® $\mathrm{Z} 1$ implants acts as a real shield against pathogenic microorganisms.

In fact, in addition to its excellent biocompatibility, its basic chemical, physical, mechanical and thermal properties enable it to meet the criteria of the ISO 13356 standard and the American Society for Testing and Materials (ASTM F 1873) ${ }^{(25)}$.

Unlike conventional bone level implants, PERIOSAVE® Z1 implants allow immediate spontaneous healing of both bone and soft tissues. Therefore, it is now possible to initiate prosthetic stages without having to re-operate on the implant site, thus considerably reducing any risk of infection.

Due to its total smoothness, the surface type of this material is of great importance in the role of antibacterial shield for this implant. The aspect of the material's surface basically depends on three factors: density, porosity and particle size. The smoother the material, the smaller the area available for pathogens and bacterial plaque to adhere to, these being two predominant risk factors in the occurrence of peri-implantitis. ${ }^{(26)}$

The management of gingival tissue, more specifically the optimization of post-surgical healing, 
is a crucial stage in successful implant and prosthetic rehabilitation. The zirconia collar of the PERIOSAVE® Z1 implants favors not only the coronal repositioning of the gingival papillae due to the specific condition of its surface, but promotes excellent adaptation of prosthetic crowns as well. Furthermore, the shade of the zirconia collars on PERIOSAVE® Z1 implants ensures a natural aesthetic quality, even when fitted on thin gums.

The ZIRCONIA transgingival collar: behaves as an antibacterial shield. zirconia collar drastically reduces bacterial colonization on the collar of PERIOSAVE® Z1 implants. The zirconia in PERIOSAVE® $\mathrm{Z} 1$ implants improves cellular adhesion and cellular proliferation (fibroblasts and osteoblasts) more than titanium: "bioactivation" property. ${ }^{(27)}$

After one-year, marginal tissue is more stable around zirconia of the PERIOSAVE® Z1 implants (zirconia-titanium technology) than around titanium implant. This increased stability has a direct correlation to the "bioactivation property" of zirconia $^{(28)}$, provides better aesthetic support of gingival tissue and creates environmental conditions for aesthetic repositioning of the mucosa and the generation of high quality epithelial attachment ${ }^{(29)}$ $.88,2 \% 5$ of PERIOSAVE® $\mathrm{Z} 1$ users are convinced by its aesthetic benefits and the simplicity of the placement procedure.94,3\%6 of PERIOSAVE® Z1 users have been able to observe natural repositioning of the papillae and the phenomenon of gingival creeping attachment. 99,6\%7 of PERIOSAVE® Z1 users have had successful fittings, without the occurrence of peri-implant diseases at two years after implantation.

\section{CONCLUSION AND RECOMMENDATIONS}

- As the success of dental implants is highly dependent on integration between implant and intraoral hard and soft tissues, so Crestal bone preservation is a very important key to success in implant dentistry.
- The use of titanium implant with transmucosal zirconium collar (Z1 TBR implant) did not show statistical significance in comparison to titanium implant with titanium collar in terms of limitation of crestal resorption usually seen after loading.

- Follow- up time 9 months seem to be not enough to determine definitive superiority of implant type on the other.

- With respect to radiographic evaluations of crestal bone levels in humans, long-term observation is required, particularly through prospective, randomized, multicenter trials with large numbers of participants.

\section{REFERENCES}

1. Ratner B. Replacing and renewing: synthetic materials, biomimetics and tissue engineering in implant dentistry. J Dent Educ 2001; 65: 1340-7.

2. Keller J. Physical and biological characteristics of implant materials. Adv Dent Res 1999; 13: 5-7.

3. Akagawa Y, Abe Y. Titanium: the ultimate solution or an evolutionary step? Int J Prosthodont 2003; 16: 47-51.

4. Buser D, Mericske-Stern R, Dula K, Lang NP. Clinical experience with one-stage, non-submerged dental implants. Adv Dent Res 1999; 13: 153-61.

5. Fiorellini JP, Buser D, Paquette DW, Williams RC, Haghighi D. A radiographic evaluation of bone healing around submerged and non submerged dental implants in beagle dog. J Periodontol 1999; 70: 24854.

6. Zechner W, Kneissel M, Kim S, Ulm C, Watzek G, Plenk $\mathrm{H}$. Histomorphometrical and clinical comparison of submerged and nonsubmerged implants subjected to experimental peri-implantitis in dog. Clin Oral Implants Res 2004; 15: 23-33.

7. Hulbert SF. The use of alumina and zirconia in surgical implants. In: Hench L, Wilson J eds. An introduction to bioceramics, advances series in ceramics. New York: World Scientific, 1993; 25-9.

8. Rimondini L, Cerroni L, Carrassi A, Torricelli P. Bacterial colonization of zirconia ceramic surfaces: an in vitro and in vivo study. Int J Oral Maxillofac Implants 2002; 6: 793-8. 
9. Grossner-Schreiber B, Griepentrog M, Haustein I. Plaque formation on surface modified dental implants. An in vitro study. Clin Oral Implants Res 2001; 6: 543-51.

10. Hisbergues M, Vendeville S, Vendeville P. Zirconia: Established facts and perspectives for a biomaterial in dental implantology J Biomed Mater Res B Appl Biomater. 2009;88(2):519-29. DOI: 10.1002/jbm.b.31147

11. Tetè S, Mastrangelo F, Bianchi A, Zizzari V, Scarano A. Collagen fiber orientation around machined titanium and zirconia dental implant necks: An animal study. Int J Oral Maxillofac Implants. 2009;24(1):528.

12. Haas, R., Pollak, Ch., Fu "rhauser, R., Mailath-Pokorny, G., Dörtbudak, O. \& Watzek, G. A long term follow up of 76 Branemark single tooth implants. Clinical Oral Implants Research 2002 13: 38-43.

13. Belser, U., Buser, D. \& Higginbottom, F. Consensus statements and recommended clinical procedures regarding esthetics in implant dentistry. International Journal of Oral \& Maxillofacial Implants 192004 (Suppl): 73-74.

14. Garber DA. The esthetic dental implant: letting restoration be the guide. Journal of Oral Implantology 1996 22: 45-50

15. Chang, M., Wennstrom, J.L., Odman, P.A. \& Andersson, B. Implant supported single-tooth replacements compared to contralateral natural teeth. Clinical Oral Implants Research 1999 10: 185-194.

16. Furhauser R, Florescu D, Benesch T, Haas R, Mailath G, Watzek G. Evaluation of soft tissue around single-tooth implant crowns: the pink esthetic score. Clin Oral Implants Res 2005:16(6):639-44.

17. Belser UC, Grutter L, Vailati F, Bornstein MM, Weber HP, Buser D. Outcome evaluation of early placed maxillary anterior single-tooth implants using objective esthetic criteria: a crosssectional, retrospective study in 45 patients with a 2- to 4-year follow-up using pink and white esthetic scores. J Periodontol 2009:80(1):140-51.

18. Naert I, Koutsikakis G, Duyck J, Quirynen M, Jacobs R, van Steenberghe D. Biologic outcome of single-implant restorations as tooth replacements: a long-term follow-up study. Clin Implant Dent Relat Res 2000; 2:209-218.

19. Binon PP. Implants and components: entering the new millennium. Int J Oral Maxillofac Implants 2000; 15:76-94.

20. Albrektsson T, Dahl E, Enbom L. Osseointegrated oral implants. A Swedish multicenter study of 8139 consecutively insertedNobelpharmaimplants. J Periodontol 1988; 59:287- 296 .

21. Heydecke G, Kohal R, Gläser R. Optimal esthetics in singletooth replacement with the re-implant system: a case report. Int J Prosthodont 1999; 12:184-189.

22. Wohlwend A, Studer S, Schärer P. das Zirkonoxidabutment - ein neues vollkeramisches Konzept zur ästhetischen Verbesserung der Suprastruktur in der Implantologie. Quintessenz Zahntechn 1996; 22:364-381.

23. Stejskal J, Stejskal VD. The role of metals in autoimmunity and the link to neuroendocrinology. Neuroendocrinal Lett 1999; 20:351-364.

24. Valentine-Thon E, Schiwara HW. Validity of MELISA for metal sensitivity testing. Neuroendocrinal Lett 2003; 24:57- 64

25. Kohal RJ, Klaus G. A zirconia implant-crown system: a case report. Int J Periodontics Restorative Dent2004; 24:147-153.

26. L Rimondini, L Cerroni, A Carrassi. Bacterial Colonization of Zirconia Ceramic Surfaces: An In vitro and In Vivo Study. The International Journal of Oral and Maxillofacial Implants 2002; 17,6.

27. AE Bianchi, M Bosetti, G Dolci Jr. In vitro and In Vivo Follow-up of titanium transmucosal implant with zirconia collar. Journal of Applied Biomaterials \& Biomechanics 2004 Vol 2, Number 3.

28. Benhamou,A. Aesthetics and implants: the contribution of the MCB. Journal of prosthetic: 1994 : 63-70

29. S Tetè, F Mastrangelo, A Bianchi. Collagen fiber orientation around machined titanium and zirconia dental implant necks: an animal study. The International Journal of Oral and Maxillofacial Implants 2009 Volume 24. 